\title{
Modulation of the tumor microenvironment by intratumoral administration of IMO-2125, a novel TLR9 agonist, for cancer immunotherapy
}

\author{
DAQING WANG, WAYNE JIANG, FUGANG ZHU, XIANZHI MAO and SUDHIR AGRAWAL \\ Idera Pharmaceuticals, Inc., Cambridge, MA 02139, USA
}

Received March 9, 2018; Accepted June 4, 2018

DOI: $10.3892 /$ ijo.2018.4456

\begin{abstract}
The objective of cancer immunotherapy is to prime the host's immune system to recognize and attack malignant tumor cells. IMO-2125, a Toll-like receptor 9 (TLR9) agonist, exhibited potent antitumor effects in the murine syngeneic A20 lymphoma and the CT26 colon carcinoma models. IMO-2125 exhibited superior A20 antitumor activity when injected intratumorally (i.t.) compared with equivalent subcutaneous doses. In mice bearing dual CT26 grafts, the i.t. injection of right flank tumors elicited infiltration of cluster of differentiation (CD) $3^{+} \mathrm{T}$ lymphocytes into tumors, resulting in the regression of injected and uninjected left flank tumors. Depletion of $\mathrm{CD}^{+}$, but not $\mathrm{CD}^{+}$, T-cells abrogated the IMO-2125-mediated antitumor response, suggesting that $\mathrm{CD}^{+}$lymphocytes are required for the antitumor activity. In mice harboring right flank CT26 and left flank $\beta$-galactosidase ( $\beta$-gal)-expressing CT26.CL25 grafts, the i.t. administration of IMO-2125 to the CT26 graft resulted in potent and dose-dependent antitumor activity against the two grafts. Splenic T-cells isolated from these mice responded to AH1 antigen (present in the two tumors) and $\beta$-gal antigen (present only in CT26. CL25) in an interferon $\gamma$ enzyme-linked immunospot assay, suggesting the clonal expansion of T-cells directed against antigens from the two tumors. Mice with ablated CT26 tumors by previous IMO-2125 treatment rejected re-implanted CT26 tumor cells, but not A20 tumor cells, demonstrating that the initial IMO-2125 treatment created a long-lived tumor-specific immune memory of CT26 antigens. A quantitative increase in $\mathrm{CD}^{+} \mathrm{T}$ lymphocytes in injected A20 tumors and an upregulation of selected checkpoint genes, including indoleamine 2,3-dioxygenase (IDO)-1, IDO-2, programmed cell death protein-1 (PD-1); programmed cell death protein
\end{abstract}

Correspondence to: Dr Daqing Wang or Dr Sudhir Agrawal, Idera Pharmaceuticals, Inc., 167 Sidney Street, Cambridge, MA 02139, USA

E-mail: dwang@iderapharma.com

E-mail: forsagrawal@gmail.com

Key words: immunotherapy, IMO-2125, abscopal effect, checkpoint, memory response, oligonucleotide, phosphorothioate ligand 1 (PD-L1), carcinoembryonic antigen-related cell adhesion molecule 1 , tumor necrosis factor receptor superfamily member 4 (OX40), OX40 ligand, T-cell immunoglobulin and mucin-domain-containing 3 protein, lymphocyte-activation gene 3 , cytotoxic T-lymphocyte-associated protein 4 , were observed following IMO-2125 treatment. IMO-2125 also increased immune checkpoint gene expression in injected and uninjected contralateral CT26 tumors, suggesting that the co-administration of anti-CTLA-4, anti-PD-1 or anti-PD-L1 therapies with IMO-2125 may provide additional therapeutic efficacy.

\section{Introduction}

In the last few years, significant progress has been made in the field of cancer immunotherapy (1). These advances have resulted in the approval of agents which target components of the immune system including cytotoxic T-lymphocyte-associated protein 4 (CTLA-4), programmed cell death protein-1 (PD-1) and programmed cell death protein ligand 1 (PD-L1). Although these agents have yielded encouraging results in a subset of patients, the majority of patients fail to respond to these therapies. Emerging data have indicated that the status of the tumor microenvironment (TME) is critical to the therapeutic outcome. Treatment is most effective in tumors that have an immunogenic environment (hot tumors) with a number of neoantigens and a high mutation load. A number of approaches are being pursued to modulate the TME such as talimogene laherparepvec, an oncolytic modified herpes simplex virus, which has been approved for the treatment of melanoma $(2,3)$. Toll-like receptor (TLR) agonists provide another mechanism for modulating TME without the inherent infectious risks that are associated with the use of oncolytic viruses.

It was recognized as early as 1893 that bacterial extracts injected into human tumors led to a decrease in tumor burden and occasionally cures (4). Later, the intratumoral (i.t.) injection of live Bacillus Calmette-Guérin (BCG) (5) was also identified to be therapeutically effective (6-10). In certain cases, the regression of distant (uninjected) metastatic cancer was also observed in patients following i.t. treatment of the primary tumor $(7,11,12)$. This notable therapeutic activity of BCG was identified to reside mainly in its nucleic acid fraction (13). Later, it was determined that bacterial nucleic acids 
contain unmethylated $\mathrm{CpG}$ dinucleotides, which activate immune responses through TLR9.

In total, 10 human TLR subtypes have been identified to date including TLR9, which is located almost exclusively on the endosomes of naïve B and dendritic cells. TLR9 is potently stimulated by DNA (or DNA mimetics) containing unmethylated $\mathrm{CpG}$ synthetic nucleotide sequences assembled to mimic those found in bacterial DNA (oligodeoxynucleotides or ODNs). Synthetic nucleic acid agonists of TLR9 signal the clonal expansion and maturation of plasmacytoid dendritic cells (14-17). As part of their activation response, plasmacytoid dendritic cells are able to secrete high levels of interferon (IFN) $\alpha$ (18), which promotes a Th1-type immune response favoring the activation of cluster of differentiation (CD) $8^{+}$killer T-cells that are crucial for an antitumor immune response.

Extensive structure-activity association studies of $\mathrm{CpG}$ ODNs have been performed to create optimized TLR9 agonists (15,19-29). One such TLR9 agonist, IMO-2125, consists of a phosphorothioate ODN sequence with three immunostimulatory dinucleotide motifs which consist of cytosine-7-deazaguanosine $\left(\mathrm{CpG}^{*}\right)$ (30). Activation of TLR9 by IMO-2125 leads to the production of Th1-type cytokines and chemokines, including high levels of IFN $\alpha$ in human peripheral blood mononuclear cell and plasmacytoid dendritic cell cultures (15). IFN $\alpha$ is a member of the type I class of interferons that produce the first line of defense against viral or bacterial infections. We have previously demonstrated the safety of subcutaneously administered IMO-2125, along with evidence for clinical activity in a phase I clinical trial in patients with hepatitis C. IMO-2125 elicited a dose-dependent increase in circulating IFN $\alpha$ levels (31). In the present study, a dually implanted syngeneic CT26 colon carcinoma model was used to demonstrate that the injection of IMO-2125 directly into one tumor leads to potent tumor regression of the injected and the uninjected distant tumors by a $\mathrm{CD} 8^{+} \mathrm{T}$-cell directed Th1 response with a long-term tumor-specific memory.

\section{Materials and methods}

Synthesis and purification of compounds. IMO-2125 is a potent synthetic ODN TLR9 agonist containing a phosphorothioate backbone with the sequence 5'-TCG*AACG*TTCG*-X-G*CT TG*CAAG*CT-5' where $\mathrm{G}^{*}$ represents 2 '-deoxy-7-deazaguanosine and $\mathrm{X}$ is a glycerol linker. A control oligonucleotide, 'IMO control', is a phosphorothioate ODN, 5'-CTATCT GUC $† G^{*}$ TCCTTCT $\underline{\text { GU-3', where }} \mathrm{G}^{*}$ is $2^{\prime}$-deoxy-7-deazaguanosine, $\mathrm{C} \dagger$ is $2^{\prime}$-deoxy-5-methylcytidine, and $\underline{\mathrm{G}}$ and $\underline{\mathrm{U}}$ are 2'-O-methylribonucleotides. The two compounds were synthesized, purified and evaluated as described previously $(15,30,32)$. The synthetic peptides $\beta$-galactosidase ( $\beta$-gal), TPHPARIGL (representing the naturally processed $\mathrm{H}-2 \mathrm{~L}^{\mathrm{d}}$ restricted epitope spanning amino acids 876-884 of $\beta$-gal) and $\mathrm{AH} 1$, SPSYVYHQF (containing a CTL determinant from CT26) were synthesized by New England Peptide, Inc. (Gardner, MA, USA), to a purity of $>99 \%$ as determined using high-performance liquid chromatography $(33,34)$.

Animals and cell lines. A total of $128 \mathrm{female} \mathrm{BALB/c}$ mice (6-8-week-old; 17-19 g) were purchased from Jackson Laboratory (Bar Harbor, ME, USA). All animal studies were approved by the Institutional Animal Care and Use Committee of Idera Pharmaceuticals, Inc. Mice were maintained under standard conditions (room temperature, $22 \pm 2^{\circ} \mathrm{C}$; relative humidity, $55 \pm 10 \%$ ) on a 12 -h light/12-h dark schedule (lights on at 6:00 a.m.). Animals had ad libitum access to food and water. All cell lines were obtained from the American Type Culture Collection (Manassas, VA, USA). CT26 is a carcinogen-induced undifferentiated syngeneic colon carcinoma (33). CT26.CL25 is a subclone of CT26 that has been transduced with the $\beta$-gal gene from Escherichia coli (33). A20 is a murine B-cell lymphoma (35). Tumor cells were cultured at $37^{\circ} \mathrm{C}$ in $5 \% \mathrm{CO}_{2}$ in RPMI-1640 medium supplemented with $10 \%$ heat-inactivated fetal bovine serum (HyClone; GE Healthcare, Logan, UT, USA), 2 mM L-glutamine, $100 \mu \mathrm{g} / \mathrm{ml}$ streptomycin and $100 \mathrm{U} / \mathrm{ml}$ penicillin (Gibco; Thermo Fisher Scientific, Inc., Waltham, MA, USA). CT26. CL25 was maintained in the culture medium with $400 \mu \mathrm{g} / \mathrm{ml}$ G418 sulfate (Invitrogen; Thermo Fisher Scientific, Inc.).

Comparative antitumor activity of i.t. and subcutaneous (s.c.) $I M O-2125$. BALB/c mice $(\mathrm{n}=8)$ were injected subcutaneously with $5 \times 10^{6}$ A20 lymphoma cells into the right flank. Treatment was initiated on day 8 when the tumor volume reached $200 \mathrm{~mm}^{3}$. PBS or IMO-2125 (50 $\mu \mathrm{g}$ in $100 \mu \mathrm{l}$ PBS, $2.5 \mathrm{mg} / \mathrm{kg}$ ) was administered to tumor-bearing mice directly into the implanted tumor (i.t.) or subcutaneously (s.c.) at a site distal to the tumor graft. Treatment was given on days $8,11,13$ and 15 . Tumor growth was determined by measuring the long and short diameters of the tumor using calipers. Tumor volume was calculated using the formula $0.5 \mathrm{x}$ length $\mathrm{x}$ width ${ }^{2}$.

Antitumor activity and dose response of IMO-2125. BALB/c mice $(n=8)$ were injected subcutaneously with $2 \times 10^{6}$ CT26 cells into the right flank and $2 \times 10^{6}$ CT26.CL25 cells into the left flank. Once the tumor volume reached between 50 and $150 \mathrm{~mm}^{3}$, treatment was initiated. IMO control $(100 \mu \mathrm{g})$ or IMO-2125 $(10,50$ or $100 \mu \mathrm{g})$ were injected into the CT26 tumor (i.t.) once every 3 days for four doses.

Tumor re-challenge in previously treated mice. Mice $(\mathrm{n}=6)$ from the $100 \mu \mathrm{g}$ IMO-2125 treatment group that exhibited complete tumor regression were re-challenged with a second subcutaneous inoculation of $1 \times 10^{6} \mathrm{CT} 26$ tumor cells into the right and left flanks on day 33. In total, 5 mice survived due to rejection of the CT26 tumor and these mice were then subcutaneously inoculated with $1 \times 10^{6}$ A20 cells on day 73 in the upper back area. Age-matched naïve BALB/c mice inoculated with $1 \times 10^{6}$ A20 $(n=5)$ served as naïve inoculation controls.

Depletion of $\mathrm{CD}^{+}$and/or $C D 8^{+}$cells. Naïve BALB/c mice (two groups, $\mathrm{n}=8$ each group) or T-cell-depleted BALB/c mice (three groups, $\mathrm{n}=5$ each group, $\mathrm{CD} 4^{+}$-depleted, $\mathrm{CD} 8^{+}$-depleted or $\mathrm{CD}^{+} / \mathrm{CD}^{+}$-co-depleted) were injected subcutaneously with $2 \times 10^{6}$ CT26 cells into the right flank and $2 \times 10^{6}$ CT26. CL25 cells into the left flank, on study day $0 . \mathrm{CD}^{+}$and/or $\mathrm{CD}^{+} \mathrm{T}$-cells were depleted by intraperitoneal injection of $25 \mathrm{mg} / \mathrm{kg}(500 \mu \mathrm{g})$ anti-mouse CD4 monoclonal antibody (mAb) (clone GK1.5; cat. no. BE0003-1), anti-mouse CD8 mAb (clone YTS 169.4; cat. no. BE0117) (both from BioXcell, West Lebanon, NH, USA), or anti-CD4 and anti-CD8 mAb 
together on days $-1,5$ and 12 . Antibodies were diluted to $2.5 \mathrm{mg} / \mathrm{ml}$ in PBS and $200 \mu \mathrm{l}$ was administered per mouse. The depletion conditions were validated by flow cytometry of peripheral blood exhibiting complete depletion of $\mathrm{CD}^{+}$and $\mathrm{CD}^{+}$T-cells. Treatment with IMO-2125 or IMO control was initiated on day 6 when the tumor volume ranged between 100 and $250 \mathrm{~mm}^{3}$. IMO-2125 or IMO control $(50 \mu \mathrm{g})$ was injected i.t into the right-flank CT26 tumor on days 6, 10 and 13 .

Flow cytometry. Fresh peripheral blood cells and single cell suspensions of splenocytes were preblocked by mouse Fc blocker (anti-mouse CD16/CD32 antibody, 1:50 dilution; cat. no. 553142; BD Biosciences, San Jose, CA, USA) then stained with fluorescently labeled anti-CD4 (1:200 dilution; cat. no. 553049) and/or anti-CD8 antibody (1:200 dilution, cat. no. 553035) (both from BD Biosciences). The stained peripheral blood cells and splenocytes were fixed/hemolysed and extensively washed prior to being analyzed using a BD Accuri flow cytometer. The flow cytometry data analysis was performed using FlowJo software (version 10; FlowJo LLC, Ashland, OR, USA).

T-cell responses by enzyme-linked immunospot (ELISPOT) assay. Splenocytes from individual tumor-bearing mouse were prepared on day 28 from $50 \mu \mathrm{g}$ IMO-2125 or IMO control groups $(n=3)$. T-cells were purified using T-cell enrichment columns (R\&D Systems, Inc., Minneapolis, MN, USA). Purified T-cells $\left(2.5 \times 10^{5}\right)$ were stimulated with $2.5 \times 10^{5}$ mitomycin C (50 $\mu \mathrm{g} / \mathrm{ml})$-treated syngeneic spleen cells pulsed with medium, $100 \mu \mathrm{g} / \mathrm{ml} \mathrm{AH1} \mathrm{peptide} \mathrm{(SPSYVYHQF)} \mathrm{or}$ $\beta$-gal peptide (TPHPARIGL) for $24 \mathrm{~h}$. The frequencies of T-cells specifically responsive to AH1 epitope in CT26 and to AH1 and $\beta$-gal epitopes in CT26.CL25 were determined in duplicate using an IFN $\gamma$ ELISPOT assay (R\&D Systems, Inc.), according to the manufacturer's protocol. Spots were enumerated with an automated ELISpot reader system (Zellnet, Port Lee, NJ, USA).

Immunohistochemistry of tumor-infiltrating $C D 3^{+} T$-cells . Injected and uninjected contralateral tumor samples were collected from mice on day 28. Formalin-fixed paraffin-embedded sections from injected and distant tumors were immunohistochemically stained for mouse T-cells by the Mass Histology Service (Worcester, MA, USA). Rabbit monoclonal anti-mouse CD3 antibody (clone SP7; cat. no. ab16669; Abcam, Cambridge, MA, USA) was used as primary antibody (1:200 dilution) and a horseradish peroxidase system was used to detect the signal. Sections from mouse spleen were used as positive controls. $\mathrm{CD}^{+}$cells in the tumor tissues were examined under a microscope, and counted in high-power fields (HPF; magnification, x400). A minimum of $10 \mathrm{HPF}$ was counted to generate a mean value per animal.

Gene expression analysis. BALB/c mice (four groups, $\mathrm{n}=5 /$ group) were subcutaneously inoculated on the flanks with $3 \times 10^{6}$ CT26 cells. On day 8 , a single i.t. injection on the right flank of PBS, $250 \mu \mathrm{g}$ IMO control, $50 \mu \mathrm{g}$ IMO-2125 or $250 \mu \mathrm{g}$ IMO-2125 was delivered. Tumor nodules from injected and distant sites were collected on day 10 and were evaluated for the expression of indoleamine 2,3-dioxygenase (IDO)-1,
IDO-2, programmed cell death protein ligand 1 (PD-L1), programmed cell death protein-1 (PD-1), carcinoembryonic antigen-related cell adhesion molecule-1 (CEACAM-1), tumor necrosis factor receptor superfamily member 4 (OX40), B- and T-lymphocyte attenuator, T-cell immunoglobulin and mucin-domain-containing-3 protein (TIM-3), lymphocyte-activation gene 3 (LAG-3), cytotoxic T-lymphocyte-associated protein 4 (CTLA-4) and OX40 ligand (OX40L). Total RNA was extracted using TRIzol ${ }^{\circledR}$ reagent (Thermo Fisher Scientific, Inc.), according to the manufacturer's protocol. Equal amounts of RNA were reverse-transcribed using a High-Capacity cDNA Reverse Transcription kit (Applied Biosystems; Thermo Fisher Scientific, Inc.). cDNAs were then amplified using the quantitative polymerase chain reaction (qPCR) using TaqMan ${ }^{\circledR}$ gene expression assays (Applied Biosystems; Thermo Fisher Scientific, Inc.). Relative gene expression was analyzed using the $2^{-\Delta \Delta C q}$ method (36). The amplification cycles were performed using a QuantStudio ${ }^{\mathrm{TM}}$ 12K Flex Real-Time PCR system (Applied Biosystems; Thermo Fisher Scientific, Inc.) as follows: $95^{\circ} \mathrm{C}$ for $20 \mathrm{sec}$, followed by 40 cycles of $95^{\circ} \mathrm{C}$ for $1 \mathrm{sec}$ and $60^{\circ} \mathrm{C}$ for $20 \mathrm{sec}$. The housekeeping gene peptidylprolyl isomerase (Ppib; probe Mm00478295_m1 Ppib VIC ${ }^{\circledR}$; Thermo Fisher Scientific, Inc.) was used as an internal control for normalization of each sample.

Statistical analysis. Statistical analysis was performed using unpaired two-tailed or one-tailed (checkpoint gene expression) Student's t-test for comparisons between two groups or a one-way analysis of variance (ANOVA) followed by either Dunnett's or Tukey's multiple comparison test was used in studies comparing more than two groups. The survival data were compared using a log-rank (Mantel-Cox) test. $\mathrm{P}<0.05$ was considered to indicate a statistically significant difference.

\section{Results}

Comparison of i.t. and s.c. IMO-2125 treatment of syngeneic A20 lymphoma. The i.t. and s.c. routes of delivery were compared in the A20 syngeneic tumor model bearing single tumor grafts on their right flank. Tumor dimensions were measured over time and the resulting tumor volumes are presented in Fig. 1A (i.t. PBS control), Fig. 1B (s.c. IMO-2125) and Fig. 1C (i.t. IMO-2125). On day 18, the mean tumor volumes were identified to be significantly different from each other using ANOVA $(\mathrm{P}<0.0001)$ followed by Tukey's multiple comparison test: PBS vs. i.t. IMO-2125 ( $\mathrm{P}<0.0001)$; PBS vs. s.c. IMO-2125 ( $\mathrm{P}<0.016)$ and s.c. IMO-2125 vs. i.t. IMO-2125 ( $\mathrm{P}=0.002)$. s.c. IMO-2125 $(50 \mu \mathrm{g})$ exhibited a minimal antitumor effect (2/8-treated mice) over time compared with PBS controls. However, tumor growth inhibition was observed over time in all 8 animals following i.t. treatment with an equal $50 \mu \mathrm{g}$ dose of IMO-2125. The number of tumor-infiltrating lymphocytes (TILs) was assessed using CD3 immunohistochemistry and representative micrographs from PBS controls (Fig. 1D), s.c. IMO-2125-treated mice (Fig. 1E) and i.t. IMO-2125 treated mice (Fig. 1F). The delivery of IMO-2125 by the i.t. route resulted in an increased number of $\mathrm{CD}^{+}$TILs into the tumor compared with the s.c. route or i.t. PBS control (Fig. 1G). 
A

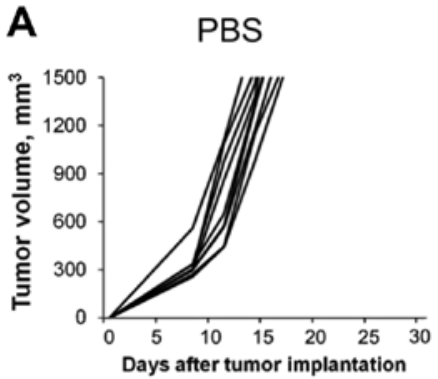

D

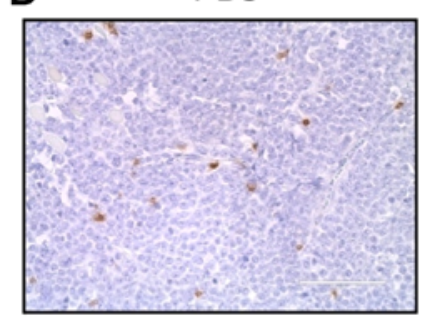

G

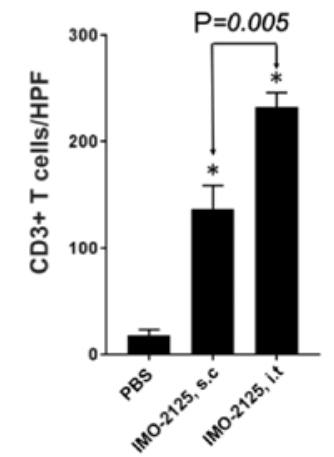

B

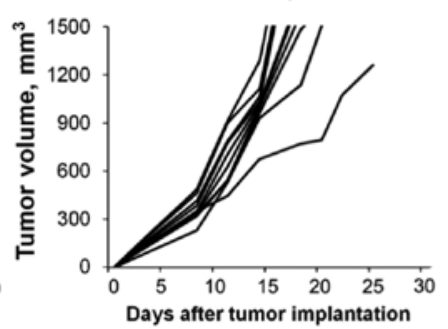

E

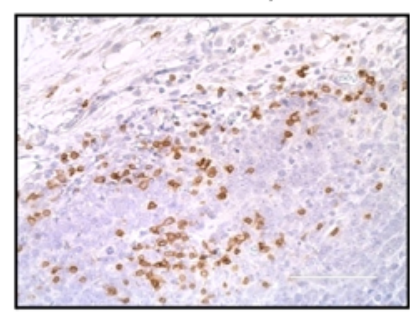

C

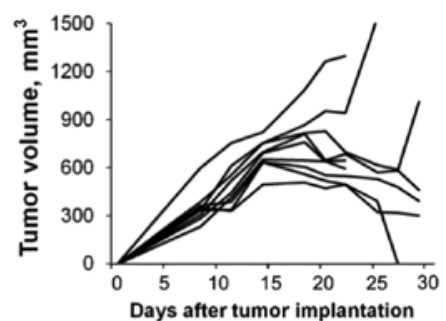

F IMO-2125, i.t.

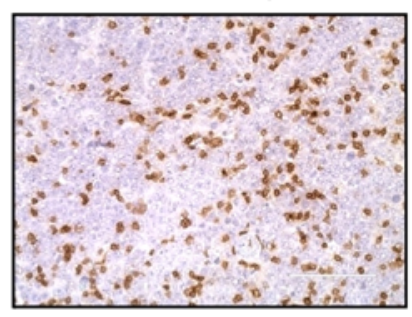

H Changes in checkpoint gene expression

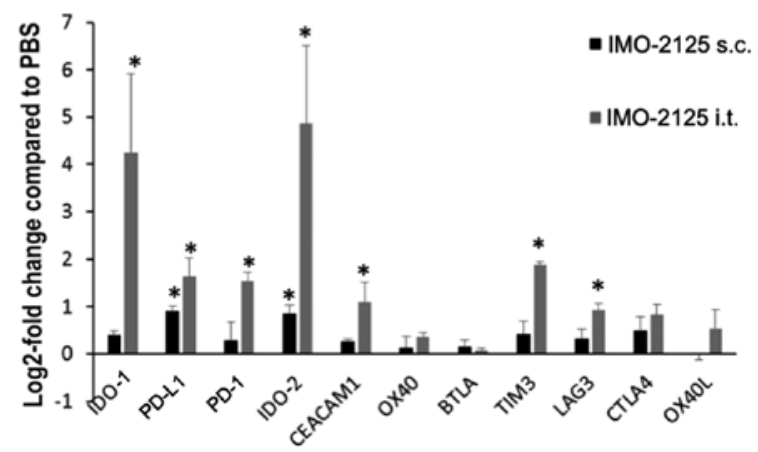

Figure 1. Comparative antitumor activity of i.t. and s.c. IMO-2125 administration. Three groups of BALB/c mice (n=9) bearing A20 lymphoma grafts $\left(\sim 200 \mathrm{~mm}^{3}\right)$ on their right flank were injected with (A) i.t. PBS, (B) $50 \mu \mathrm{g}$ s.c. IMO-2125 or (C) $50 \mu \mathrm{g}$ i.t. IMO- 2125 on days $8,11,13$ and 15 , and tumor volumes were determined to day 30 . On day 18 , the mean tumor volumes were significantly different from each other by analysis of variance $(\mathrm{P}<0.0001)$ followed by Tukey's multiple comparison test: PBS vs. i.t. IMO-2125 ( $\mathrm{P}<0.0001)$; PBS vs. s.c. IMO-2125 ( $\mathrm{P}<0.016)$ and s.c. IMO-2125 vs. i.t. IMO-2125 (P=0.002), Tumors were processed, sectioned and stained to detect the $\mathrm{CD}^{+} \mathrm{T}$-cells. T-cells staining positively for $\mathrm{CD} 3$ antigen are indicated by punctate brown staining in representative A20 tumor sections from mice injected with (D) i.t. PBS, (E) $50 \mu \mathrm{g}$ s.c. IMO-2125 or (F) $50 \mu \mathrm{g}$ i.t. IMO-2125. Scale bar, $100 \mu \mathrm{m}$. (G) CD3 ${ }^{+}$ T-cell staining. " $\mathrm{P}<0.05$ vs. PBS group. (H) Alterations in checkpoint gene expression. " $\mathrm{P}<0.05$ vs. s.c. IMO-2125. i.t., intratumoral; s.c., subcutaneous; $\mathrm{CD}$, cluster of differentiation; HPF, high-power field; IDO, indoleamine 2,3-dioxygenase; PD-L1, programmed cell death protein ligand 1; PD-1, programmed cell death protein-1; CEACAM1, carcinoembryonic antigen-related cell adhesion molecule 1; OX40, tumor necrosis factor receptor superfamily member 4; BTLA, B- and T-lymphocyte attenuator; TIM3, T-cell immunoglobulin and mucin-domain-containing 3 protein; LAG3, lymphocyte-activation gene 3; CTLA, cytotoxic T-lymphocyte-associated protein 4; OX40L, OX40 ligand.

Comparison of changes in checkpoint gene expression in i.t or s.c. injected A20 lymphoma. Compared with systemic s.c. administration, i.t. IMO-2125 resulted in significantly increased modulation of checkpoint gene expression (Fig. 1H). The fold increase in gene expression in A20 tumors (50 $\mu \mathrm{g}$ group) from i.t. treated mice compared with s.c. treated mice was 3.8 for IDO-1, 3.1 for IDO-2, 1.4 for PD-L1, 2.0 for PD-1, 1.6 for CEACAM-1, 1.2 for OX40, 2.0 for TIM-3, 1.5 for LAG-3, 1.2 for CTLA-4 and 1.6 for OX40L.

i.t. IMO-2125 treatment leads to abscopal effects. IMO-2125 injected directly (i.t.) into right flank CT26 syngeneic colon tumor grafts of mice also bearing uninjected left flank CT26. CL25 tumor grafts on days 5, 8, 11 and 14 resulted in a significant growth suppression of the two tumors in a dose-dependent manner (Fig. 2A and B). A one-way ANOVA conducted to compare the mean tumor volumes on day 28 in the treatment groups with the IMO control group demonstrated a significant difference between groups. Tumor growth of the injected CT26 tumor was inhibited 15.4, 79.6 and $94.7 \%$ at respective doses of $10(0.5 \mathrm{mg} / \mathrm{kg}), 50(2.5 \mathrm{mg} / \mathrm{kg})$ and $100(5 \mathrm{mg} / \mathrm{kg}) \mu \mathrm{g}$ IMO-2125 compared with IMO control on day 28 . The growth of uninjected CT26.CL25 tumors, were similarly inhibited 18, 65.6 and $93.2 \%$ at doses of 10,50 and $100 \mu \mathrm{g}$, respectively, compared with control group on day 28. Treated and distant tumors injected with 50 and $100 \mu \mathrm{g}$ IMO-2125 exhibited a significant decrease in tumor growth $(\mathrm{P}<0.01)$ compared with the tumors in IMO control group. The degree of tumor growth inhibition was dose-dependent, and complete ablation $\left(<100 \mathrm{~mm}^{3}\right.$ consisting mostly of scar tissue) of the injected and uninjected tumors was observed in none of the 8 mice in the IMO control group, none of the 8 mice in the $10-\mu \mathrm{g}$ dose-group, 2 of 8 mice in the 

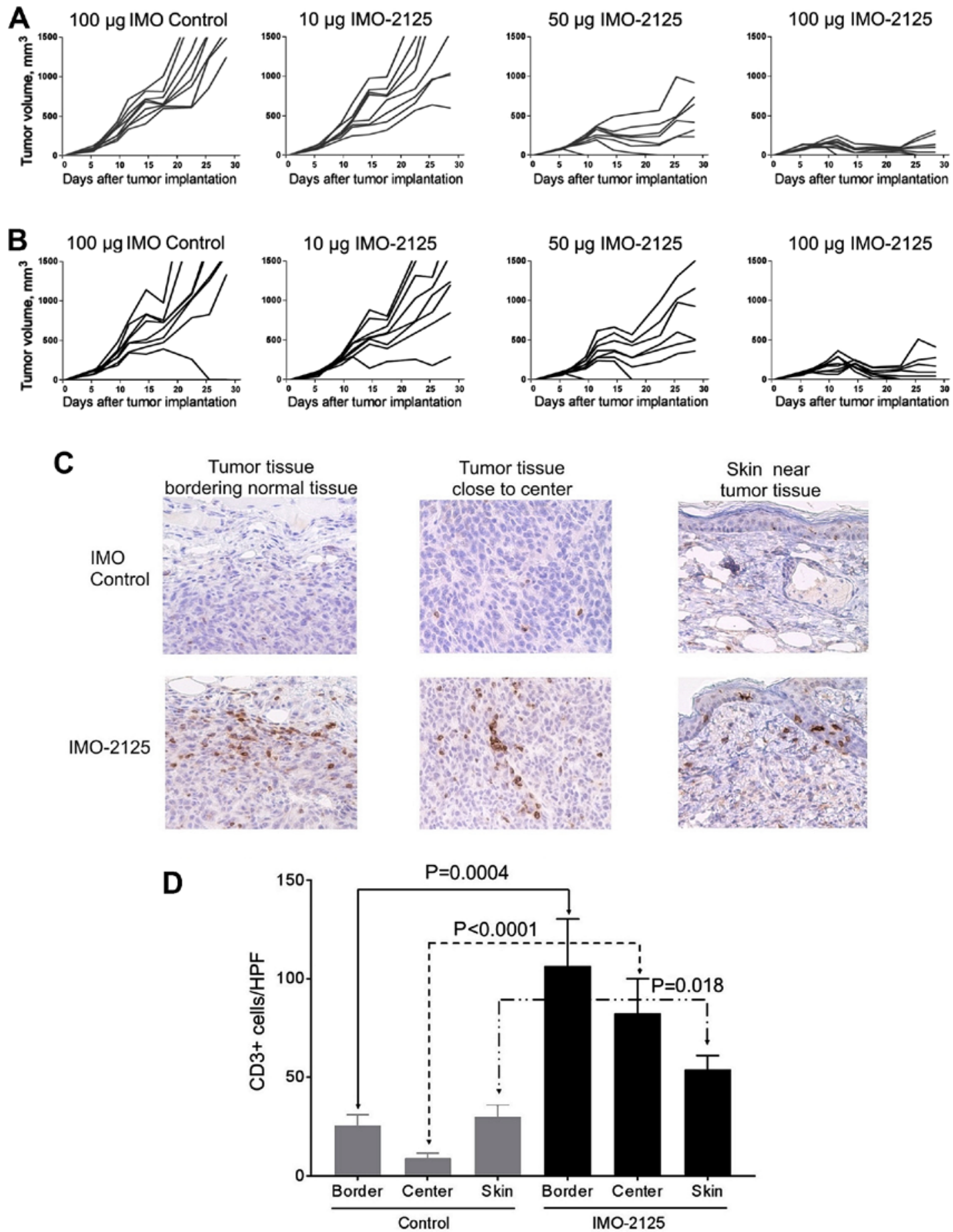

Figure 2. Treatment with i.t. IMO-2125 of a single CT26 tumor graft produces a dose-dependent systemic inhibition of tumor growth in injected and uninjected contralateral tumors, associated with increased infiltration of $\mathrm{CD}^{+} \mathrm{T}$-cells. $\mathrm{BALB} / \mathrm{c}$ mice (four groups, $\mathrm{n}=8$ each group) were implanted with subcutaneous tumor cells CT26 on the right flank and CT26.CL25 (a subclone of CT26 engineered to express an antigenic $\beta$-galactosidase fragment) on the left flank. The right flank CT26 tumor in each group was injected i.t. with IMO control $(100 \mu \mathrm{g})$ or 10,50 or $100 \mu \mathrm{g} \mathrm{IMO-2125}$ on days 5, 8, 11 and 14 . Tumor volumes for each individual animal in (A) left flank-injected CT26 tumor grafts and (B) right flank-uninjected CT26.CL25 grafts. (C) The mice were sacrificed on day 28, the tumors were collected from mice treated in the IMO control (upper) and $50 \mu \mathrm{g} \mathrm{IMO-2125} \mathrm{(lower)} \mathrm{and} \mathrm{CD3}{ }^{+} \mathrm{T}$-cells were stained. (D) Increased tumor infiltration of $\mathrm{CD}^{+} \mathrm{T}$-cells in IMO-2125-injected tumors associated with IMO-2125-induced tumor growth inhibition. Results are presented as the mean \pm standard error of the mean. i.t, intratumoral; CD, cluster of differentiation; HPF, high-power field.

$50-\mu \mathrm{g}$ dose-group and 5 of 8 mice in the 100- $\mu$ g dose-group on day 28. Tumor volumes for the injected (Fig. 2A) and uninjected contralateral (Fig. 2B) tumors of each individual animal are presented. The five mice with ablated tumors in the $100-\mu \mathrm{g}$ dose group were used in subsequent re-challenge experiments to determine tumor-specific immune memory. All other mice were sacrificed on day 28 and selected tumors from each group were used for CD3 immunohistochemical staining studies.

i.t. IMO-2125 leads to increased $C D 3^{+} T$-cell infiltration. The presence of TILs was determined by immunohistochemical staining of $\mathrm{CD}^{+}$T-cells in tumors treated with IMO control 

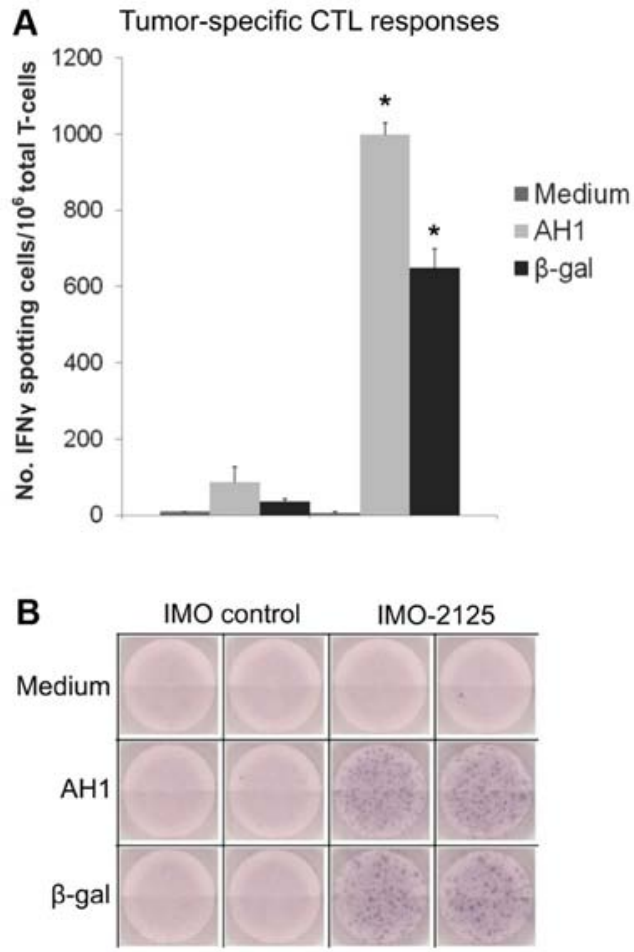

Figure 3. Treatment with i.t. IMO-2125 elicits tumor antigen-specific cytotoxic T-cells. Splenic T-cells were isolated from animals in IMO control and IMO-2125 treatment groups on day 28. T-cells were purified from splenocytes in each group and were stimulated with mitomycin C-treated syngeneic spleen cells pulsed with medium, AH1 peptide (present in injected CT26 and uninjected CT26.CL25), or $\beta$-gal peptide (present in uninjected CT26. CL25 only) for $24 \mathrm{~h}$. T-cells specially responding to stimulation with CT26 and CT26.CL25 tumor antigens AH1 and $\beta$-gal were enumerated using IFN $\gamma$ enzyme-linked immunospot assay. (A) Quantification and (B) duplicate representative plate images for each treatment group. IMO-2125 i.t. injections on CT26 elicited specific cytotoxic T-cells to CT26-associated antigen AH1 $(\mathrm{P}<0.001)$ and to $\beta$-gal in CT26.CL25 implanted in the distant side $(\mathrm{P}<0.001)$. i.t., intratumoral; $\beta$-gal, $\beta$-galactosidase; CTL, cytotoxic T lymphocyte; IFN, interferon.

and $50 \mu \mathrm{g}$ i.t. IMO-2125. In total, three samples were taken from each tumor: The edge of the tumor bordering normal muscle tissue, central tumor tissue and tumor tissue near the skin. A limited number of $\mathrm{CD}^{+}$cells was observed from samples taken from the i.t. IMO control group (Fig. 2C, upper panels). In contrast, mice treated i.t with IMO-2125 exhibited a marked increase in the number of $\mathrm{CD}^{+} \mathrm{T}$-cells in the tumor tissue from all three regions (Fig. 2D), indicating that the antitumor activity of IMO-2125 was associated with the increased infiltration of TILs. Representative micrographs of uninjected CT26.CL25 tumor samples are presented in the lower panels of Fig. 2C.

i.t. IMO-2125 induces cytotoxic T-cell responses against treated and distant tumors. The splenic T-cell responses to tumor antigens (AH1 and $\beta$-gal) were determined in mice from the IMO control or $50 \mu \mathrm{g}$ IMO-2125 treatment groups on day 28. The tumor internal antigen (AH1, present in CT26 and CT26.CL25) and $\beta$-gal (present only in CT26.CL25) were used as challenge peptide antigens in the ELISPOT assay. In total, 3 mice in each of IMO control or $50 \mu \mathrm{g}$ IMO-2125 treatment groups were sacrificed on day 28. T-cells isolated from splenocytes were stimulated with mitomycin C-treated syngeneic spleen cells pulsed with medium, AH1 or $\beta$-gal peptide for $24 \mathrm{~h}$. The number of T-cells responding to antigen challenge in the IMO-2125-treated and IMO control mice are quantified in Fig. 3A, and representative images of ELISPOT plates indicating IFN $\gamma$-positive spots are presented in Fig. 3B. i.t. IMO-2125 in the single CT26 tumor induced significant increases in tumor antigen-specific IFN $\gamma$-secreting effector cell responses against the CT26 endogenous antigen, AH1, and also against the $\beta$-gal antigen that existed in the distant CT26.CL25 tumor. In contrast, IMO control-treated mice displayed negligible T-cell responses to either of the peptide challenges $(\mathrm{P}<0.001)$.

Treatment with IMO-2125 induces a durable tumor-specific response. Animals from the high-dose group that exhibited complete tumor regression following $100 \mu \mathrm{g}$ i.t. IMO-2125 treatment $(n=5)$ were re-implanted with $1 \times 10^{6}$ CT26 tumor cells on day 33 to determine the duration of T-cell memory. Age-matched naïve BALB/c mice inoculated with $1 \times 10^{6} \mathrm{CT} 26$ cells $(n=5)$ were used as controls. IMO-2125-treated tumor-free mice developed tumor-specific protections and rejected certain tumor (CT26) re-challenge (Fig. 4A). However, such immune memory was tumor-specific and the same mice that rejected CT26 implantation were not protected from syngeneic non-organ-associated A20 lymphoma challenge (Fig. 4B).

Antitumor activity of IMO-2125 is dependent on CD8 ${ }^{+}$ $T$-cells. The association between IMO-2125-mediated antitumor activity and the requirement of $\mathrm{CD} 4^{+}$and $\mathrm{CD} 8^{+} \mathrm{T}$-cells was investigated in groups of mice depleted of $\mathrm{CD}^{+}$and/or $\mathrm{CD} 8^{+} \mathrm{T}$-cells by intraperitoneal injection of anti-mouse CD4 $\mathrm{mAb}$ or anti-mouse CD8 mAb. Fluorescence-activated cell sorting analysis of spleen cells was used to demonstrate the effective depletion of $\mathrm{CD}^{+}$lymphocytes and $\mathrm{CD} 8^{+}$ lymphocytes (Fig. 5A). All mice exhibited CT26 tumors on their right flank and CT26.CL25 tumors on their left flank. In non-T-cell-depleted mice, IMO-2125 administered i.t. into the right flank CT26 tumor resulted in a robust inhibition of tumor growth in CT26 and CT26.CL25 tumors compared with IMO control. No inhibition of tumor growth was observed by i.t. IMO-2125 treatment in mice depleted of $\mathrm{CD} 8^{+} \mathrm{T}$-cells in either of their tumor grafts, suggesting that $\mathrm{CD} 8^{+} \mathrm{T}$-cells are required for the antitumor activity of IMO-2125. Interestingly, depletion of $\mathrm{CD}^{+} \mathrm{T}$-cells resulted in a more robust antitumor response to IMO-2125 treatment compared with IMO-2125 treatment in naïve mice (Fig. 5B), possibly due to the removal of regulatory T-cells that are inhibitory to antitumor immune response.

IMO-2125 treatment leads to modulation of checkpoint gene expression. Immune checkpoint gene expression levels were evaluated using qPCR in mice bearing subcutaneous CT26 tumors following a single i.t. injection of either $50 \mu \mathrm{g}$ or $250 \mu \mathrm{g}$ IMO-2125, or $250 \mu \mathrm{g}$ IMO control 8 days after tumor inoculation. Mice treated with IMO-2125 exhibited slower tumor growth in the injected and uninjected contralateral CT26 tumors that was evident even 2 days after IMO-2125 injection (on day 10) (Fig. 6A). Mice were sacrificed and the tumors were removed for immune checkpoint gene expression studies on day 10 (Fig. 6A). The checkpoint gene expression of 

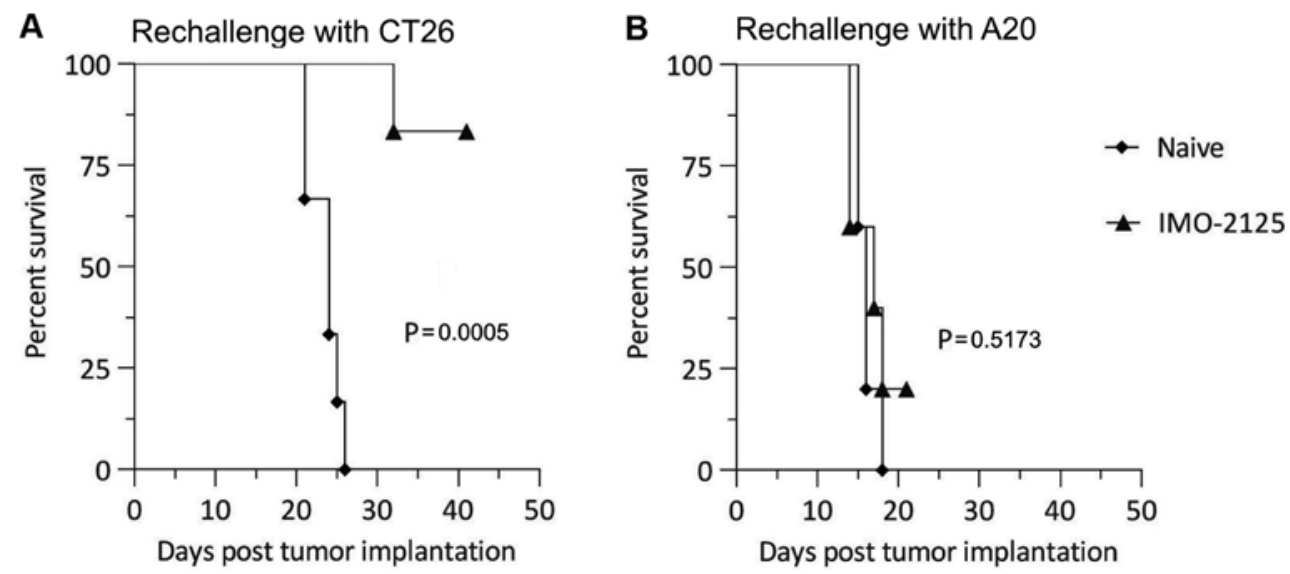

Figure 4. IMO-2125-treated long-term tumor-free survival develops tumor-specific protection and rejected re-challenge with the same tumor type. (A) Mice with complete tumor regression from the $100 \mu \mathrm{g}$ IMO-2125 treatment group (triangles, $\mathrm{n}=6$ ) re-challenged with $10^{6} \mathrm{CT} 26$ tumor cells on day 33 exhibited significantly improved survival compared with age-matched naïve BALB/c mice implanted with $10^{6} \mathrm{CT} 26$ tumor cells (diamonds, $\mathrm{n}=6$; $\mathrm{P}=0.0005$ ). (B) The 5 surviving mice from the tumor re-challenge were then inoculated with $10^{6}$ A20 lymphoma cells on day 73 and their survival was not significantly different from that of age-matched naïve BALB/c mice also inoculated with $10^{6}$ A20 lymphoma cells (diamonds, $\mathrm{n}=5 ; \mathrm{P}=0.5173$ ). Statistical analysis was performed using a log-rank (Mantel-Cox) test.

A Anti-CD4-mAb treated

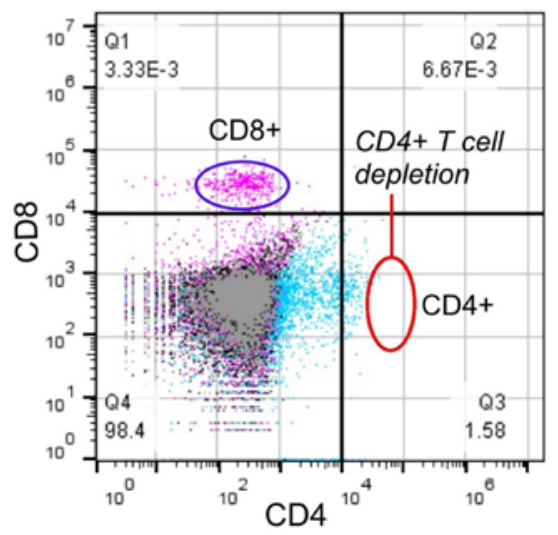

B

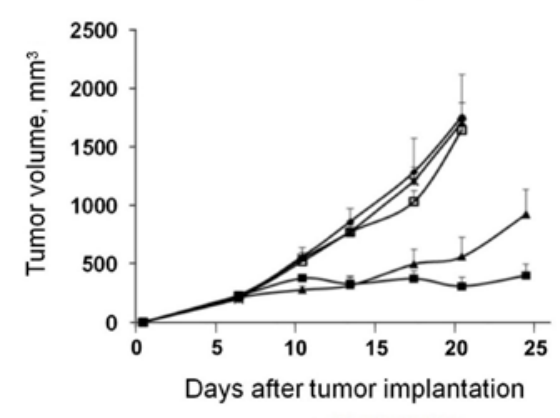

$\rightarrow$ Control oligo

$\pm \mathrm{BALB} / \mathrm{c}$ mice +2125

\section{Anti-CD8-mAb treated}

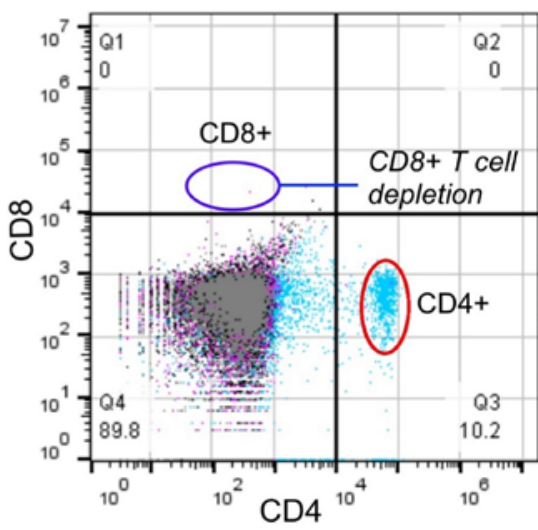

Distant tumor

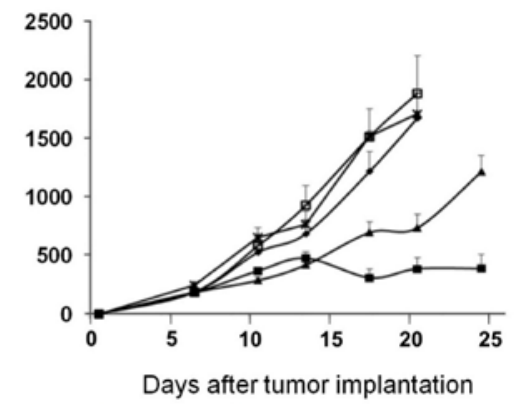

- $-\mathrm{CD} 4+$ depletion +2125

$\rightarrow$ CD $8+$ depletion +2125

Figure 5. Antitumor activity of i.t. IMO-2125 is dependent on $\mathrm{CD} 8^{+} \mathrm{T}$-cells. Mice with bilateral CT26 tumor grafts were injected i.t. into the right flank tumor with $50 \mu \mathrm{g}$ IMO control or IMO-2125 on days 6,10 and $13 . \mathrm{CD}^{+}$or $\mathrm{CD}^{+}$, or CD4 ${ }^{+}$and $\mathrm{CD} 8^{+} \mathrm{T}$ lymphocytes were depleted by the intraperitoneal administration of $25 \mathrm{mg} / \mathrm{kg}$ anti-CD4 or anti-CD8 antibodies. (A) Depletion by anti-CD4 (left) or anti-CD8 (right) monoclonal antibodies was validated by flow cytometry. (B) Tumor volumes (mean \pm standard error of the mean) from mice treated with IMO control (diamonds, $n=8$ ), IMO-2125 (triangles, $n=8$ ), CD4 depletion and IMO-2125 (filled squares, n=5), CD8 depletion and IMO-2125 (open squares, n=5), or CD4 and CD8 depletion, and IMO-2125 (crosses, $\mathrm{n=5}$ ) in injected (left) and uninjected contralateral tumors (right). i.t., intratumoral; CD, cluster of differentiation; oligo, oligonucleotide.

IDO-1, PD-L1, CEACAM-1 and OX40 in cDNA preparations from excised tumors was determined by qPCR as presented in Fig. 6B $(n=3)$. A dose-dependent increase in IDO-1, PD-L1 and CEACAM1 gene expression was observed, although it was 
A

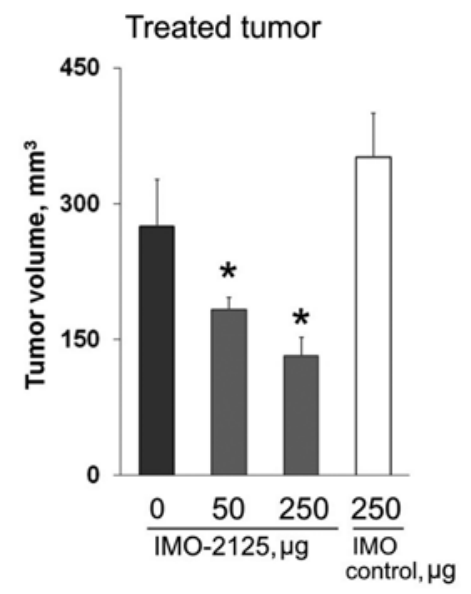

B

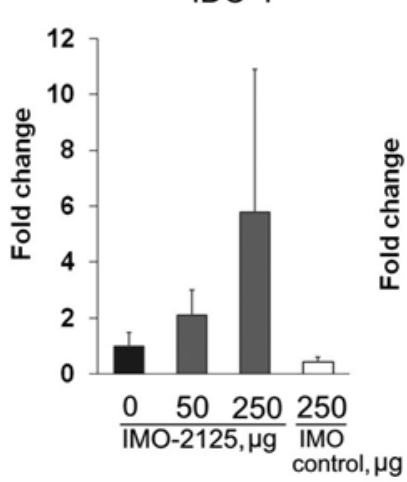

PD-L1

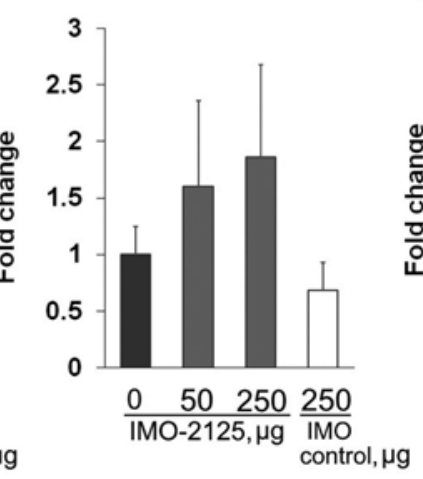

Distant tumor

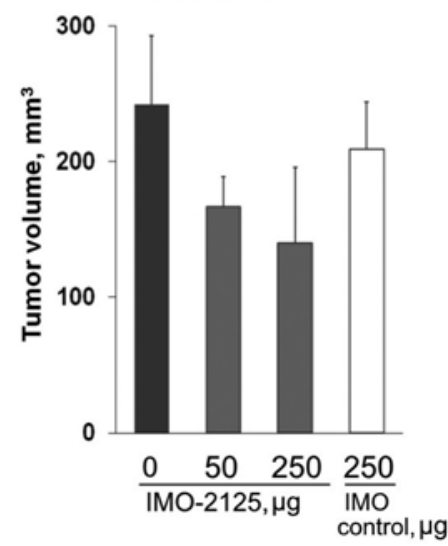

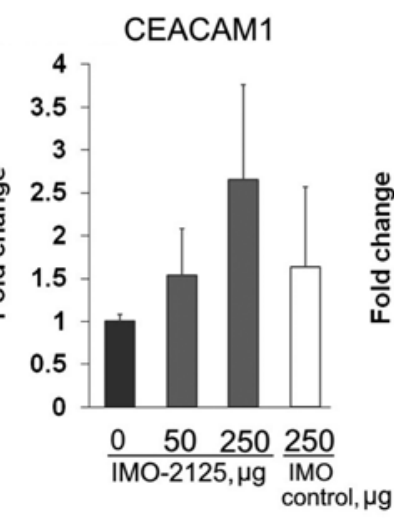

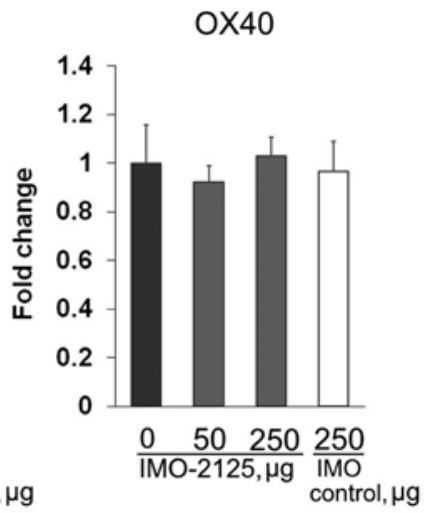

Figure 6. Treatment with i.t. IMO-2125 leads to modulation of immune checkpoint gene expression. (A) Tumor volumes on day 10 of bilaterally implanted mice bearing CT26 tumor grafts following a single i.t. injection on day 8 into the right flank tumor with PBS, $50 \mu \mathrm{g}$ IMO $-2125(2.5 \mathrm{mg} / \mathrm{kg}), 250 \mu \mathrm{g}$ IMO-2125 $(12.5 \mathrm{mg} / \mathrm{kg}$ ) or $250 \mu \mathrm{g} \mathrm{IMO} \mathrm{control} \mathrm{in} \mathrm{the} \mathrm{injected} \mathrm{tumor} \mathrm{on} \mathrm{the} \mathrm{right} \mathrm{flank} \mathrm{(left)} \mathrm{or} \mathrm{the} \mathrm{uninjected} \mathrm{tumor} \mathrm{on} \mathrm{the} \mathrm{left} \mathrm{flank} \mathrm{(right).} \mathrm{Tumor} \mathrm{volumes} \mathrm{are}$ presented as the mean \pm SEM ( $n=5$, each group). ${ }^{*} \mathrm{P}<0.05$ vs. PBS. (B) Alterations in checkpoint gene expression from uninjected tumors are depicted as the mean \pm SEM fold change over IMO control levels for IDO-1, PD-L1, CEACAM-1 and OX40. i.t., intratumoral; SEM, standard error of the mean; IDO, indoleamine 2,3-dioxygenase; PD-L1, programmed cell death protein ligand 1; CEACAM1, carcinoembryonic antigen-related cell adhesion molecule 1; OX40, tumor necrosis factor receptor superfamily member 4 .

not statistically significant. OX40 was not altered $48 \mathrm{~h}$ after a single dose. The lack of statistical significance is possibly due to tumor tissue sampling.

\section{Discussion}

IMO-2125 is a potent synthetic oligonucleotide designed to activate TLR9 by initiating a strong Th1-polarized immune response. In the present study, it was identified that the direct i.t. administration of IMO-2125 into murine A20 lymphoma tumor grafts led to increased antitumor activity compared with equal doses administered subcutaneously. This observation is consistent with the hypothesis that immunostimulatory drugs target immune cells in the TME and prime the immune system to recognize cancer cells as foreign. TLR9 is located on the endosomes of plasmacytoid dendritic cells and B-cells that respond to IMO-2125 stimulation through the induction of Th1 cytokines including interleukin-12, IFN $\alpha$ and $\operatorname{IFN} \gamma(15,30,31)$. Mature dendritic cells located in the TME act as sentries to recognize bacterial and viral DNA and may be key cells that initiate the receptor mediated immune response to i.t. injection of IMO-2125. Clinical trials are currently being conducted using i.t. IMO-2125 in patients with cancer (clinicaltrials.gov identifiers NCT03052205, NCT03445533 and NCT02644967).
IMO-2125 is composed of two 11-mer phosphorothioate oligonucleotides, covalently linked via their 3'-ends, which each contain three appropriately placed $\mathrm{CpG}^{*}$ motifs ( $\mathrm{G}^{*}$ representing 7-deazaguanosine). The resulting palindromic sequence form double-stranded secondary structures with 5 ' overhangs on each end. This unique structure facilitates the dimerization of the compound and thereby potentiates the activation of the Th1 pathway associated with increased IFN $\alpha$ induction $(15,30,31)$.

The i.t. delivery of IMO-2125 to a single tumor site led to systemic antitumor responses at uninjected distal tumors. Thus, targeting IMO-2125 directly to the TME by i.t injection resulted in systemic efficacy. This delivery route allows IMO-2125 to act as a danger signal within a local tumor compartment, triggering antigen recognition by antigen-presenting cells, and causing the host immune system to recognize and attack the injected tumor. In the present study, a syngeneic colon carcinoma model with the CT26 colon graft on one flank and a CT26.CL25 subclone engineered to express an additional antigenic fragment of $\beta$-gal on the opposite flank was used. The i.t. administration of IMO-2125 to the CT26 graft on one flank resulted in potent and equivalent antitumor activity at the injected CT26 graft as well as the uninjected CT26.CL25 distal tumor in a dose-dependent manner. 
Immunohistochemical staining of $\mathrm{CD}^{+}$, a marker of infiltrating $\mathrm{T}$ lymphocytes, exhibited increased densities of $\mathrm{CD}^{+}$ T-cells in the central and peripheral regions of injected CT26 and uninjected CT26.CL25 tumor grafts compared with IMO controls. Depletion of CD8 ${ }^{+} \mathrm{T}$ lymphocytes with CD8-specific antibodies abrogated the antitumor response, whereas depletion of $\mathrm{CD}^{+}$lymphocytes with CD4-specific antibodies did not, suggesting that IMO-2125 primarily elicited a $\mathrm{CD}^{+}$ T-cell-mediated response indicative of Th1 polarization. Interestingly, the treatment of $\mathrm{CD}^{+}{ }^{+}$-depleted mice with IMO-2125 led to an antitumor response that was more marked compared with that observed in IMO-2125-treated mice with no $\mathrm{T}$ lymphocyte depletion, suggesting that $\mathrm{CD}^{+}$regulatory $\mathrm{T}$ lymphocytes may negatively modulate the immunotherapeutic response of IMO-2125.

ELISPOT assays indicated that T-cells purified from the spleens of dually implanted CT26/CT26.CL25 mice responded equally well to $\mathrm{AH} 1$ or $\beta$-gal antigens, even though the $\beta$-gal antigen was only expressed in the uninjected CT26. CL25 subclone. Thus, a clonal expansion of T-cells responsive to the two tumor-specific antigens (AH1 expressed in the two tumors and $\beta$-gal expressed only in the CT26.CL25 subclone) occurred in response to i.t. IMO-2125 administration. These results further suggested that the i.t. injection of IMO-2125 was able to initiate antigen spreading by cells present in the injected and the uninjected tumors. Activated splenic T-cells were quantified in the ELISPOT assay by their release of IFN $\gamma$ upon stimulation with AH1 or $\beta$-gal. IFN $\gamma$ is also an important cytokine in the Th1 response that is reported to lead to the M1 polarization of immunostimulatory macrophages rather than the M2 immunosuppressive macrophages (37), so it is possible that IMO-2125 supports M1 macrophage polarization directed against tumor antigens.

IMO-2125 has been identified to induce surface marker expression and the activation of human dendritic cells and B-cells, as well as increased levels of IFNa in vitro and in vivo $(15,30)$. In clinical trials, IMO-2125 elicited a potent dose-dependent increase in systemic IFN $\alpha$ and other Th1-type cytokines in patients with hepatitis $\mathrm{C}$ at doses that were well-tolerated following systemic administration (31). Interferons are known to interact with specific cellular receptors, which promote the production of second messengers leading to expression of immune modulatory genes. Type I interferons activate the majority of immune cells including macrophages, dendritic cells, B-cells and T-cells to suppress cancer. They are also able to upregulate the expression of tumor antigens $(38,39)$, stimulate the presentation of antigens by dendritic cells $(40,41)$, and promote optimal effector function of both $\mathrm{CD} 8^{+} \mathrm{T}$-cells and natural killer cells $(42,43)$.

Immune checkpoints are ligand-receptor pairs that feedback signals to properly balance the immune response to rid the body of abnormal cells while protecting normal cells from an autoimmune attack. However, neoplastic progression and transformation often involve the epigenetic modification of genes that allow cancer cells to escape immune surveillance $(44,45)$. The therapeutic approach to cancer treatment has expanded to include drugs that reverse the immune tolerance that cancer cells develop. In the last decade, immunotherapy has been demonstrated to improve the survival of a subset of patients with advanced cancers. The US Food and Drug
Administration-approved ipilimumab (CTLA-4-blocking antibody), nivolumab and pembrolizumab (PD-1-blocking antibodies), and atezolizumab and durvalumab (PD-L1-blocking antibodies) have led to favorable outcomes in a subset of patients (46-51). It has become increasingly evident that the TME must be in a receptive state for cancer immunotherapy to be successful (52). IMO-2125 may provide the stimulus to create a more receptive TME and thereby improve the efficacy of immune checkpoint inhibitors currently approved and in clinical trials $(53,54)$.

Immune checkpoints protect against excessive activation though a feedback loop and are therefore upregulated during an inflammatory response. For example, the checkpoint inhibitors CTLA-4, PD-1, PD-L1 and IDO-1 negatively modulate the immune system's ability to attack cancerous tumors allowing for their continuous growth and potential metastasis (55). Previous studies have identified increased expression levels of CTLA-4 and PD-1 in TILs of patients with metastatic melanoma compared with those of healthy donors (56). Other studies have also demonstrated that activation of TLR9 by $\mathrm{CpG}$ ODN agonists leads to the expression of IDO-1 in dendritic cells $(57,58)$. In the present study, it was identified that i.t. IMO-2125 treatment increased the levels of mRNA for various immune checkpoint inhibitors including PD-1, PD-L1 and CEACAM-1 above IMO control-treated levels in A20 and CT26 tumors. In addition, increased CTLA-4 gene expression levels in the A20 tumor 20 days after initiation of IMO-2125 treatment was also identified. The upregulation of checkpoint gene expression levels following i.t. IMO-2125 treatment suggests that IMO-2125 co-administered with checkpoint inhibitors may lead to additive or synergistic antitumor activity compared with monotherapies. Clinical trials are currently in progress evaluating i.t. IMO-2125 monotherapy and IMO-2125 in combination with ipilimumab, an anti-CTLA-4 antibody, or in combination with pembrolizumab, an anti-PD-1 antibody, in patients previously treated for metastatic melanoma (clinicaltrials.gov identifiers NCT03052205, NCT03445533 and NCT02644967).

In summary, these studies suggest that IMO-2125 is a potent synthetic TLR9 agonist that activates TLR9 on B-cells and dendritic cells in the TME to initiate and potentiate a Th1-polarized local and systemic immune response when administered by i.t. injection. The i.t. injection of IMO-2125 to a single tumor site led to systemic and equivalent antitumor responses at uninjected contralateral tumors suggesting that treatment with IMO-2125 may effectively treat primary and metastatic disease when injected into one tumor lesion. Indeed, in an ongoing trial of i.t. IMO-2125 in combination with ipilimumab, certain patients exhibited responses in injected and metastatic lesions (59). The stimulation of TLR9 by IMO-2125 by the i.t. route of administration led to a tumor-specific immune response in the injected and uninjected tumors requiring $\mathrm{CD}^{+}$, but not $\mathrm{CD}^{+}$, $\mathrm{T}$ lymphocytes. The immunostimulatory modulation of IMO-2125 was accompanied by an upregulation of immune checkpoint genes including IDO-1, PD-L1, CEACAM-1 and CTLA-4, suggesting that feedback inhibition by these checkpoints may negatively modulate the immunostimulatory effects of IMO-2125. Thus, although IMO-2125 exhibited potent antitumor activity as a monotherapy, the co-administration of approved immune 
checkpoint inhibitors with IMO-2125 may provide additive or synergistic antitumor efficacy.

A phase I/II clinical trial of i.t. IMO-2125 in combination with ipilimumab or pembrolizumab in patients with anti-PD-1 refractory melanoma is ongoing (NCT02644967), and encouraging evidence of changes in immune markers and clinical activity has been observed for the ipilimumab combination $(59,60)$. A phase III trial is in progress (NCT03445533). In addition, a phase I trial of i.t. IMO-2125 monotherapy in refractory solid tumors (NCT03052205) is also ongoing.

\section{Acknowledgements}

The authors thank Jillian DiMuzio (Idera Pharmaceuticals, Inc., Cambridge, MA, USA) and Evren K. Argon (Idera Pharmaceuticals, Inc.) for assistance with qPCR analysis, Katherine Worsham (Idera Pharmaceuticals, Inc.) for editing and administrative assistance, and Carol A. Nelson (Translational Pharmacology Consulting, Westford, MA, USA) for assistance with the manuscript preparation.

\section{Funding}

Funding was provided by Idera Pharmaceuticals, Inc.

\section{Availability of data and materials}

The datasets used and analyzed during the current study are available from the corresponding author on reasonable request.

\section{Authors' contributions}

DW and SA designed and directed the project. DW, WJ, FZ and XM performed the experiments. DW and SA took the lead in writing the manuscript. All authors provided critical feedback and helped shape the research, analysis and manuscript.

\section{Ethics approval and consent to participate}

All animal studies were approved by the Institutional Animal Care and Use Committee of Idera Pharmaceuticals, Inc.

\section{Patient consent for publication}

Not applicable.

\section{Competing interests}

The authors declare that they have no competing interests.

\section{References}

1. Alexander W: The Checkpoint Immunotherapy Revolution What started as a trickle has become a flood, despite some daunting adverse effects; New drugs, indications, and combinations continue to emerge. PT 41: 185-191, 2016.

2. Fountzilas C, Patel S and Mahalingam D: Review: Oncolytic virotherapy, updates and future directions. Oncotarget 8: 102617-102639, 2017.

3. Yin J, Markert JM and Leavenworth JW: Modulation of the intratumoral immune landscape by oncolytic herpes simplex virus virotherapy. Front Oncol 7: 136, 2017.
4. Coley WB: The treatment of malignant tumors by repeated inoculations of erysipelas. With a report of ten original cases. 1893. Clin Orthop Relat Res 262: 3-11, 1991.

5. Zbar B and Tanaka T: Immunotherapy of cancer: Regression of tumors after intralesional injection of living Mycobacterium bovis. Science 172: 271-273, 1971.

6. Cohen MH, Jessup JM, Felix EL, Weese JL and Herberman RB: Intralesional treatment of recurrent metastatic cutaneous malignant melanoma: A randomized prospective study of intralesional Bacillus Calmette-Guerin versus intralesional dinitrochlorobenzene. Cancer 41: 2456-2463, 1978.

7. Morton DL, Eilber FR, Holmes EC, Hunt JS, Ketcham AS, Silverstein MJ and Sparks FC: BCG immunotherapy of malignant melanoma: Summary of a seven-year experience. Ann Surg 180: 635-643, 1974.

8. Silverstein MJ, DeKernion J and Morton DL: Malignant melanoma metastatic to the bladder. Regression following intratumor injection of BCG vaccine. JAMA 229: 688, 1974.

9. Krown SE, Hilal EY, Pinsky CM, Hirshaut Y, Wanebo HJ, Hansen JA, Huvos AG and Oettgen HF: Intralesional injection of the methanol extraction residue of Bacillus Calmette-Guerin (MER) into cutaneous metastases of malignant melanoma. Cancer 42: 2648-2660, 1978.

10. Bier J, Kleinschuster S, Bier H and Rapp H: Intratumor immunotherapy with BCG cell wall preparations: Development of a new therapy approach for head-neck tumors. Arch Otorhinolaryngol 236: 245-255, 1982 (In German).

11. Bast RC Jr, Zbar B, Borsos T and Rapp HJ: BCG and cancer (first of two parts). N Engl J Med 290: 1413-1420, 1974.

12. Bast RC Jr, Zbar B, Borsos T and Rapp HJ: BCG and cancer. N Engl J Med 290: 1458-1469, 1974.

13. Shimada S, Yano O, Inoue H, Kuramoto E, Fukuda $T$, Yamamoto H, Kataoka T and Tokunaga T: Antitumor activity of the DNA fraction from Mycobacterium bovis BCG. II. Effects on various syngeneic mouse tumors. J Natl Cancer Inst 74: 681-688, 1985.

14. Yamamoto S, Yamamoto T, Nojima Y, Umemori K, Phalen S, McMurray DN, Kuramoto E, Iho S, Takauji R, Sato Y, et al: Discovery of immunostimulatory CpG-DNA and its application to tuberculosis vaccine development. Jpn J Infect Dis 55: 37-44, 2002.

15. Yu D, Kandimalla ER, Bhagat L, Tang JY, Cong Y, Tang J and Agrawal S: 'Immunomers' - novel 3'-3'-linked CpG oligodeoxyribonucleotides as potent immunomodulatory agents. Nucleic Acids Res 30: 4460-4469, 2002.

16. Hemmi H, Takeuchi O, Kawai T, Kaisho T, Sato S, Sanjo H, Matsumoto M, Hoshino K, Wagner H, Takeda K, et al: A Toll-like receptor recognizes bacterial DNA. Nature 408: 740-745, 2000.

17. Krieg AM, Yi AK, Matson S, Waldschmidt TJ, Bishop GA, Teasdale R, Koretzky GA and Klinman DM: CpG motifs in bacterial DNA trigger direct B-cell activation. Nature 374: 546-549, 1995.

18. Mandl JN, Barry AP, Vanderford TH, Kozyr N, Chavan R, Klucking S, Barrat FJ, Coffman RL, Staprans SI and Feinberg MB: Divergent TLR7 and TLR9 signaling and type I interferon production distinguish pathogenic and nonpathogenic AIDS virus infections. Nat Med 14: 1077-1087, 2008.

19. Zhao Q, Temsamani J, Iadarola PL, Jiang Z and Agrawal S: Effect of different chemically modified oligodeoxynucleotides on immune stimulation. Biochem Pharmacol 51: 173-182, 1996.

20. Kandimalla ER, Yu D, Zhao Q and Agrawal S: Effect of chemical modifications of cytosine and guanine in a CpG-motif of oligonucleotides: Structure-immunostimulatory activity relationships. Bioorg Med Chem 9: 807-813, 2001.

21. Yu D, Zhao Q, Kandimalla ER and Agrawal S: Accessible 5'-end of CpG-containing phosphorothioate oligodeoxynucleotides is essential for immunostimulatory activity. Bioorg Med Chem Lett 10: 2585-2588, 2000.

22. Kandimalla ER, Bhagat L, Yu D, Cong Y, Tang J and Agrawal S: Conjugation of ligands at the 5'-end of CpG DNA affects immunostimulatory activity. Bioconjug Chem 13: 966-974, 2002.

23. Kandimalla ER, Bhagat L, Wang D, Yu D, Zhu FG, Tang J, Wang H, Huang P, Zhang R and Agrawal S: Divergent synthetic nucleotide motif recognition pattern: Design and development of potent immunomodulatory oligodeoxyribonucleotide agents with distinct cytokine induction profiles. Nucleic Acids Res 31: 2393-2400, 2003.

24. Yu D, Kandimalla ER, Zhao Q, Bhagat L, Cong Y and Agrawal S: Requirement of nucleobase proximal to $\mathrm{CpG}$ dinucleotide for immunostimulatory activity of synthetic CpG DNA. Bioorg Med Chem 11: 459-464, 2003. 
25. Wang D, Li Y, Yu D, Song SS, Kandimalla ER and Agrawal S: Immunopharmacological and antitumor effects of secondgeneration immunomodulatory oligonucleotides containing synthetic CpR motifs. Int J Oncol 24: 901-908, 2004.

26. Damiano V, Caputo R, Bianco R, D'Armiento FP, Leonardi A, De Placido S, Bianco AR, Agrawal S, Ciardiello F and Tortora G: Novel toll-like receptor 9 agonist induces epidermal growth factor receptor (EGFR) inhibition and synergistic antitumor activity with EGFR inhibitors. Clin Cancer Res 12: 577-583, 2006.

27. Damiano V, Caputo R, Garofalo S, Bianco R, Rosa R, Merola G, Gelardi T, Racioppi L, Fontanini G, De Placido S, et al: TLR9 agonist acts by different mechanisms synergizing with bevacizumab in sensitive and cetuximab-resistant colon cancer xenografts. Proc Natl Acad Sci USA 104: 12468-12473, 2007.

28. Damiano V, Garofalo S, Rosa R, Bianco R, Caputo R, Gelardi T, Merola G, Racioppi L, Garbi C, Kandimalla ER, et al: A novel toll-like receptor 9 agonist cooperates with trastuzumab in trastuzumab-resistant breast tumors through multiple mechanisms of action. Clin Cancer Res 15: 6921-6930, 2009.

29. Rosa R, Melisi D, Damiano V, Bianco R, Garofalo S, Gelardi T, Agrawal S, Di Nicolantonio F, Scarpa A, Bardelli A, et al: Toll-like receptor 9 agonist IMO cooperates with cetuximab in $\mathrm{K}$-ras mutant colorectal and pancreatic cancers. Clin Cancer Res 17: 6531-6541, 2011.

30. Yu D, Putta MR, Bhagat L, Dai M, Wang D, Trombino AF Sullivan T, Kandimalla ER and Agrawal S: Impact of secondary structure of toll-like receptor 9 agonists on interferon alpha induction. Antimicrob Agents Chemother 52: 4320-4325, 2008.

31. Rodriguez-Torres M, Ghalib RH, Gordon SC and McHutchison JG: IMO-2125, a TLR9 agonist, induces immune responses which correlate with reductions in viral load in null responder HCV patients. Hepatology 52: 336A, 2010.

32. Kandimalla ER, Bhagat L, Wang D, Yu D, Sullivan T, La Monica N and Agrawal S: Design, synthesis and biological evaluation of novel antagonist compounds of Toll-like receptors 7 , 8 and 9. Nucleic Acids Res 41: 3947-3961, 2013.

33. Wang M, Bronte V, Chen PW, Gritz L, Panicali D, Rosenberg SA and Restifo NP: Active immunotherapy of cancer with a nonreplicating recombinant fowlpox virus encoding a mode tumor-associated antigen. J Immunol 154: 4685-4692, 1995.

34. Huang AY, Gulden PH, Woods AS, Thomas MC, Tong CD Wang W, Engelhard VH, Pasternack G, Cotter R, Hunt D, et al: The immunodominant major histocompatibility complex class I-restricted antigen of a murine colon tumor derives from an endogenous retroviral gene product. Proc Natl Acad Sci USA 93 9730-9735, 1996.

35. Touitou V,Daussy C,Bodaghi B,Camelo S, de Kozak Y,Lehoang P, Naud MC, Varin A, Thillaye-Goldenberg B, Merle-Béral H, et al: Impaired th1/tc1 cytokine production of tumor-infiltrating lymphocytes in a model of primary intraocular B-cell lymphoma. Invest Ophthalmol Vis Sci 48: 3223-3229, 2007.

36. Livak KJ and Schmittgen TD: Analysis of relative gene expression data using real-time quantitative PCR and the 2(- $\Delta \Delta \mathrm{C}(\mathrm{T}))$ method. Methods 25: 402-408, 2001.

37. Duluc D, Corvaisier M, Blanchard S, Catala L, Descamps P, Gamelin E, Ponsoda S, Delneste Y, Hebbar M and Jeannin P. Interferon-gamma reverses the immunosuppressive and protumoral properties and prevents the generation of human tumor-associated macrophages. Int J Cancer 125: 367-373, 2009.

38. Greiner JW, Hand PH, Noguchi P, Fisher PB, Pestka S and Schlom J: Enhanced expression of surface tumor-associated antigens on human breast and colon tumor cells after recombinant human leukocyte alpha-interferon treatment. Cancer Res 44: 3208-3214, 1984.

39. Boyer CM, Dawson DV, Neal SE, Winchell LF, Leslie DS Ring D and Bast RC Jr: Differential induction by interferons of major histocompatibility complex-encoded and non-major histocompatibility complex-encoded antigens in human breast and ovarian carcinoma cell lines. Cancer Res 49: 2928-2934, 1989.

40. Schiavoni G, Mattei F and Gabriele L: Type I interferons as stimulators of DC-mediated cross-priming: Impact on anti-tumor response. Front Immunol 4: 483, 2013.

41. Joffre OP, Segura E, Savina A and Amigorena S: Crosspresentation by dendritic cells. Nat Rev Immunol 12: 557-569, 2012 .
42. Nguyen KB, Salazar-Mather TP, Dalod MY, Van Deusen JB, Wei XQ, Liew FY, Caligiuri MA, Durbin JE and Biron CA: Coordinated and distinct roles for IFN-alpha beta, IL-12, and IL-15 regulation of NK cell responses to viral infection. J Immunol 169: 4279-4287, 2002.

43. Herberman RB, Ortaldo JR, Rubinstein M and Pestka S: Augmentation of natural and antibody-dependent cell-mediated cytotoxicity by pure human leukocyte interferon. J Clin Immunol 1: 149-153, 1981.

44. Liu M, Zhou J, Chen Z and Cheng AS: Understanding the epigenetic regulation of tumours and their microenvironments: Opportunities and problems for epigenetic therapy. J Pathol 241: $10-24,2017$

45. Dunn J and Rao S: Epigenetics and immunotherapy: The current state of play. Mol Immunol 87: 227-239, 2017.

46. Ott PA, Hodi FS and Robert C: CTLA-4 and PD-1/PD-L1 blockade: New immunotherapeutic modalities with durable clinical benefit in melanoma patients. Clin Cancer Res 19: 5300-5309, 2013

47. Mahoney KM, Freeman GJ and McDermott DF: The next immune-checkpoint inhibitors: PD-1/PD-L1 blockade in melanoma. Clin Ther 37: 764-782, 2015.

48. Postow MA, Callahan MK and Wolchok JD: Immune checkpoint blockade in cancer therapy. J Clin Oncol 33: 1974-1982, 2015.

49. Khalil DN, Smith EL, Brentjens RJ and Wolchok JD: The future of cancer treatment: Immunomodulation, CARs and combination immunotherapy. Nat Rev Clin Oncol 13: 273-290, 2016.

50. Serra-Bellver P, Valpione S and Lorigan P: Sequential immunotherapy regimens-expect the unexpected. Lancet Oncol 17: 854-855, 2016

51. Weber JS, Gibney G, Sullivan RJ, Sosman JA, Slingluff CL Jr, Lawrence DP, Logan TF, Schuchter LM, Nair S, Fecher L, et al: Sequential administration of nivolumab and ipilimumab with a planned switch in patients with advanced melanoma (CheckMate 064): An open-label, randomised, phase 2 trial. Lancet Oncol 17: 943-955, 2016.

52. Devaud C, John LB, Westwood JA, Darcy PK and Kershaw MH: Immune modulation of the tumor microenvironment for enhancing cancer immunotherapy. OncoImmunology 2: e25961, 2013.

53. Arpaia $\mathrm{N}$ and Barton GM: Toll-like receptors: Key players in antiviral immunity. Curr Opin Virol 1: 447-454, 2011.

54. Iwasaki A and Medzhitov R: Toll-like receptor control of the adaptive immune responses. Nat Immunol 5: 987-995, 2004.

55. Pardoll DM: The blockade of immune checkpoints in cancer immunotherapy. Nat Rev Cancer 12: 252-264, 2012.

56. Ahmadzadeh M, Johnson LA, Heemskerk B, Wunderlich JR, Dudley ME, White DE and Rosenberg SA: Tumor antigenspecific CD8 T cells infiltrating the tumor express high levels of PD-1 and are functionally impaired. Blood 114: 1537-1544, 2009

57. Mellor AL, Baban B, Chandler PR, Manlapat A, Kahler DJ and Munn DH: Cutting edge: $\mathrm{CpG}$ oligonucleotides induce splenic $\mathrm{CD}_{19}{ }^{+}$dendritic cells to acquire potent indoleamine 2,3-dioxygenase-dependent $T$ cell regulatory functions via IFN Type 1 signaling. J Immunol 175: 5601-5605, 2005.

58. Fallarino F and Puccetti P: Toll-like receptor 9-mediated induction of the immunosuppressive pathway of tryptophan catabolism. Eur J Immunol 36: 8-11, 2006.

59. Diab A, Haymaker C, Uemura M, Murthy R, James M, Geib J, Cornfeld M, Swann S, Yee C, Wargo J, et al: A phase $1 / 2$ trial of intratumoral (i.t.) IMO-2125 (IMO) in combination with checkpoint inhibitors (CPI) in PD-(L)1-refractory melanoma. Ann Oncol 28 (Suppl 5): 1187P, 2017.

60. Haymaker C, Uemura M, Murthy R, James M, Wang D, Brevard J, Swann S, Geib J, Cornfeld M, Chunduru S, et al: Translational evidence of reactivated innate and adaptive immunity with intratumoral IMO-2125 in combination with systemic checkpoint inhibitors from a phase I/II study in patients with anti-PD-1 refractory metastatic melanoma. Cancer Res 77 (Suppl 13): 5652, 2017. 